\title{
HEREDITARY SPASTIC PARAPLEGIA
}

\author{
BY
}

\author{
EDWIN R. BICKERSTAFF
}

\author{
From the Department of Neurology, United Birmingham Hospitals
}

The family under consideration in this paper has been studied in detail, not only because its members provide many examples of a disease which is very rare in this country, but also because the differing clinical picture appearing in certain members of the family may contribute to the better understanding of the hereditary disorders of the central nervous system, and their possible inter-relationship. The tendency for the members of this family to remain in the same part of the same city, even after marriage, has made it possible to examine the majority of the living members, and clinical details have been obtained concerning several who have died.

It is evident that the disease is widespread throughout three generations, and possibly four, and that alongside examples of the fully developed syndrome, there are numerous early or abortive cases. A noteworthy occurrence was the appearance in an otherwise neurologically normal member of the worst-affected branch of the family of a typical retrobulbar neuritis. This case was seen both in the acute phase and while progressing to an optic atrophy. A probably similar occurrence was noted in a cousin, and sufficient abnormality of the discs seen in two other members of the family for the suspicion of a retrobulbar neuritis to have been raised.

\section{The English Families}

Though the first description of hereditary spastic paraplegia is usually ascribed to Strümpell (1880) there seems little doubt that the same, or a closely related pathological process was responsible for the condition described by Seeligmüller (1876) four years earlier, the main clinical difference being the presence of widespread general wasting, which may well have been an atrophy of disuse. Since these early reports a large literature has accumulated, excellent reviews of which are given by Rhein (1916), Paskind and Stone (1933), and Bell and Carmichael (1939), and there is little to be gained by further repetition here. Any study of the published cases, however, shows the great majority to be in the continental journals, particularly those from Germany. Families are described in the central and southern American journals, others from the United States, and isolated reports came from Russia and Japan. In Great Britain, however, the disease appears to be rare, and indeed, despite an intensive search, Bell and Carmichael (1939) were able to find one family only amongst the records of the last 25 years at the National Hospital, Queen Square, London, and the Maida Vale Hospital, London. (If one holds to strict diagnostic criteria, the disease is less common in other countries than appears, for it would seem, as Bell and Carmichael (1939) observe, that the major justification for the clinical differentiation of this condition from the spastic ataxias is the absence of any form of ataxia-a rule not always observed.)

A number of families affected by the disease have however been reported in this country.

Philip (1886) described a family illustrating linkage between two hereditary disorders, the father and one son developing typical spastic paraplegia, while the other son and a member of an earlier generation showed the pseudo-hypertrophic form of muscular dystrophy.

Gee (1889) described a father and two sons, all being affected from infancy, if not from birth, with a severe spasticity unassociated with ataxia, while there were other congenital abnormalities in the father's mother's family.

Tooth (1891), considering four new cases of his own in conjunction with Gee's, concluded that hereditary spastic paraplegia was probably a clinical entity, though post-mortem studies were not then available.

Holmes' (1905) family had two (and possibly three) members who had a spastic paraplegia of early onset combined with localized muscle wasting. $\mathrm{He}$ thought at that time that Seeligmüller's cases might present a different condition, the wasting being generalized and possibly a disuse atrophy.

The eight cases described by Jones (1907) were all members of one sibship of nine, four having the right side mainly affected. He lays stress on the maintenance of power despite the spasticity. 
Ogilvie (1908) presented to the Royal Society of Medicine the case of a girl showing spastic paraplegia without ataxia, whose two sisters were similarly affected. It is interesting that this patient was reputed to have been ataxic four years earlier. In the discussion following, Dr. Guthrie stated that he attended a family in which the father and three of five children showed spasticity without ataxia.

Manson's (1920) cases both showed mild ataxia and nystagmus in addition to the spasticity and probably should not be included under this heading.

No further examples have been traced in the English literature until the one family described by Bell and Carmichael (1939). Three of four sisters were affected, the two who were examined showing signs of marked pyramidal disease with posterior column affection but no ataxia, while a third, not seen, was said to have disseminated sclerosis. The parents were second cousins and the onset of symptoms in the three cases occurred at ages 19 , 30 , and 40 respectively.

A familial spastic paraplegia was studied by Worster-Drought and others (1940 and 1944), but their cases showed an accompanying presenile dementia, the syndrome being caused apparently by a hyaline change in the vessels and resultant demyelination, and so differing considerably from the pathological changes usually found in hereditary spastic paraplegia.

\section{The Present Investigation}

Attention was first drawn to the existence of this family when II.9 (Fig. 1) was referred to Professor P. C. P. Cloake's clinic in 1940, and later admitted to the Queen Elizabeth Hospital for investigation of his paraplegia. At first his condition suggested a diagnosis of disseminated sclerosis, but the discovery that other members of his family were reputed to be similarly affected led to the conclusion that this was, in fact, an example of one of the heredo-familial disorders of the central nervous system. With his death from a cerebral hæmorrhage in 1944 no further contact was made with his relatives until his grandson was brought to the Neurological Clinic at the General Hospital, Birmingham, in 1948. The child's mother gave the story that her husband, her brother-in-law, and this infant had all developed the same condition as her father-in-law. It was decided to examine the father and the normal son, and the discovery that the latter had a typical retrobulbar neuritis was of such great interest that a more extensive investigation was embarked upon to include all the siblings of the original patient (II.9), their children and their grandchildren. This was carried out personally, each patient being written to, the purpose of the investigation explained, and an invitation to attend as an out-patient for examination extended.

In the three generations with whom personal contact has been possible, there have been 76 individuals, of whom 20 have died. Of the remaining 56, 43 have been examined, while 13 were on active service with high medical categories, untraced, living out of the country, or unwilling to attend. It is notable that three only came into this last group.

\section{Criteria for Diagnosis}

In the course of investigation of such a family, the diagnosis of the fully-developed case of the disease presents little difficulty. The patient's stiff but not ataxic gait seen first on entering the examina-

\section{THE "F" FAMILY}

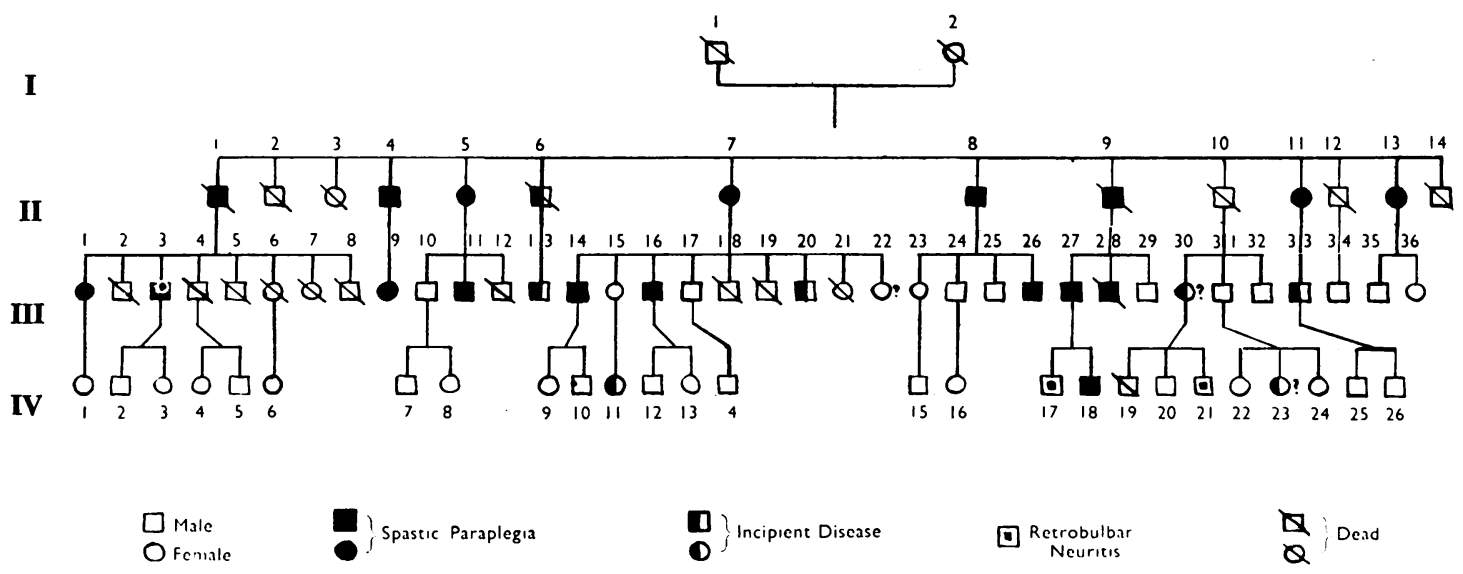

Fig. 1.-Genealogical table of family under discussion. 
tion room ; his complaints of stiffness on climbing stairs, "numbness" of the legs, weakness, uncontrollable shaking, nocturnal flexion, tripping, wearing out the toes of the shoes; and the finding of spastic limbs usually with well-preserved power whose reflexes are markedly exaggerated, one or both plantars extensor, coordination good but vibration sense diminished in the legs, all combine to make an easily recognizable picture. To this must be added the deformity of the feet found in many cases, which, though akin to pes cavus, differed in that whereas the toes were retracted, and the foot shortened antero-posteriorly with convexity upwards of the dorsum, yet the expected concavity of the plantar surface was reduced and apparently filled in by soft tissue, tending to disappear entirely when the patient stood erect so that the imprint of the foot was normal. A difference in the deformity of the foot in cases of spastic paraplegia from the well-known pes cavus of the hereditary ataxias was noted by Bell and Carmichael (1939) from their study of the literature, and Tooth (1891) had remarked that in a member of his family " the feet present the appearance of pes cavus but the arching disappears when he stands on the feet". This is again mentioned by Jones (1907), and Appel (1949) refers to a foot deformity similar to that seen in Friedreich's ataxia, but less marked, and not typical. This appears particularly liable to occur in hereditary spastic paraplegia.

This investigation was intended also to discover whether early, incomplete, or abortive forms of the disease existed in apparently unaffected members of the family, and many problems thus arose. It is necessary to exert self-discipline and avoid too great a diagnostic enthusiasm, for while it is a great advantage for purposes of comparison for one neurologist to examine all the members of a family, yet the temptation then arises to consider very slight deviations from the normal as examples of incipient disease. This applies particularly to the assessment of tendon reflexes. It is a well-known fact that nervousness is often accompanied by hyper-active reflexes, and at a first medical examination it is not infrequent for patients to exhibit considerable nervousness, particularly when they are aware that the examiner is searching for signs of a disease, the drastic late results of which they have witnessed in their relatives. Even ankle-clonus can be present under such circumstances, and many motorists will testify that following some alarming experience attempts to rest the feet upon the pedals may result in uncontrollable shaking of the limb.

Exaggerated reflexes alone were not therefore considered evidence of incipient disease. It was required that exaggeration be very marked and accompanied by some other feature or features of the fully-established condition, e.g., subjective symptoms of stiffness, uncontrollable shaking, or occasionally numbness; increase in tone (itself a difficult sign to assess), the characteristic foot deformity, long-sustained clonus or abnormal plantar responses. By these criteria several members whose reflexes appeared pathologically brisk have not been included as early cases, though in one of the two most extensive families previously $\stackrel{0}{\leftrightarrow}$ investigated (Dobrochtow, 1913), the presence of exaggerated reflexes only was considered evidence of incipient disease, while Appel (1949) more recently has adopted similar criteria.

A very careful examination of the fundi was made in all cases, for though optic atrophy is rarer in hereditary spastic paraplegia than in the ataxias, the finding of a retrobulbar neuritis in one member led to a search for similar findings or sequelæ. Pallor of the discs is so variable and indefinite a sign, however, that it was decided to adopt the attitude taken by Bell (1933) and never diagnose optic atrophy from pallor of the discs alone, unless visual failure was present. Similarly blurring of the edges of the discs was not considered definitely abnormal unless accompanied by visual failure, or known to progress to atrophy. In this way severak doubtful abnormalities have not been included in the genealogical table, but their presence is noted in the case histories.

\section{Clinical Data}

Though, as has been mentioned above, this family has remained within a small area, comparatively little contact with one another has been maintained, and conflicting statements were made by different persons regarding the health of the same relatives. The greatest difficulty was experienced in respect of Generation I,* for though the father of Generation II was known to have been perfectly well apart from bilateral cataract in later life, no other accurate information was obtainable about any of his siblings or his parents. The mother of Generation II also led a healthy life. She was an only child, but had several step-brothers and sisters, one of the former being reported by one member of the family to have suffered from similar "leg-trouble" but according to another member to have appeared quite fit in later life.

\section{Generation II (14 members)}

II.1 M. Died 1932 of tuberculosis. Leg trouble since childhood, frequently stumbling; left leg mainly affected; walked exactly like II.9 in later life.

\footnotetext{
* Numbers refer to genealogical table, Fig. 1 ; ages when first seen unless otherwise stated.
} 
II.2 M. Died in infancy, cause unknown.

II.3 F. Died in infancy, cause unknown.

II.4 M. Age 66. Affected since 36. First episode probably prolapsed lumbar disc ; still occasional pain. Increasing stiffness, shuffling gait, unsteadiness descending hills. Arthritis of knees. Gait spastic, no ataxia. Cranial nerves, arms, trunk normal. Slight general wasting lower limbs, marked spasticity, exaggerated knee and ankle jerks, left plantar abnormal. Vibration sense diminished at ankles.

II.5 F. Age 64. Lame 24 years. Increasing stiffness, contracture of hamstrings. Pain and swelling right knee. Jumping and involuntary flexion left leg. 1944 treated by extension, later attempted arthrodesis right knee but developed infected joint. Obese. Cranial nerves normal. Arm reflexes much exaggerated. Right knee not examined fully owing to chronic infective process. Left also swollen and arthritic. Bilateral increase of tone. Left knee and ankle jerks and right ankle jerk exaggerated. Right plantar equivocal, left extensor. Vibration sense absent ankles. Bilateral foot deformity.

II.6 M. Died aged 54 (1944) of pneumonia. Son's description of increasing lameness in later life, with many falls, one severe, suggests involvement to some degree.

II.7 F. Age 60. Fifteen years tendency to fall, difficulty climbing stairs, unsteadiness downhill, pains in knees. Obese. Arthritis of shoulders and knees. Cranial nerves normal. Very exaggerated arm reflexes. Absent abdominal reflexes. Increased tone left leg. Weakness dorsiflexion foot. Knee jerks much exaggerated. Bilateral extensor plantars. Gait spastic; no ataxia.

II.8 M. Age 59. Worked in India most of life. Lameness since 50. Complained only of dragging legs. Gait grossly spastic with adductor contractures. Marked euphoria in face of grave disability. Cranial nerves, arms, trunk normal. Hip movements and right leg grossly spastic. Contracture adductors and gastrocnemii. Power good. Reflexes much exaggerated. Right plantar equivocal, left extensor. Vibration sense absent ankles, diminished at knees.

II.9 M. (The first member seen at this (C 7150) neurological unit.) Age 48 (1940). History of tuberculosis 1920-23. Left hip gave way July, 1940. Increasing weakness left leg since; trembles when weight-bearing, drags, catches on pavements and trips him up. Nocturnal frequency of micturition. Gait spastic. " Only slight ataxia." Cranial nerves and arms normal except for wasting of the thenar eminences. Abdominal reflexes absent. Wasting left thigh $\frac{3}{4}$ in. Bilateral spasticity of legs ; weakness left leg ; exaggerated knee and ankle jerks, bilateral extensor plantars. "Only very slight ataxia on left." C.S.F., W.R., $x$-ray examination of spine, all normal findings. B.P. $190 / 115 \mathrm{~mm}$. Seen again 1944 when thought to have swelling left disc ; arm reflexes now exaggerated. Found unconscious December, 1944 ; died of cerebral hæmorrhage. Necropsy details not available.

II.10 M. Dead. Little information. Not known to be affected.

II.11 F. Age 51. No complaints except aching (G 273039) right knee. Mild euphoria. Very slight choroidal degeneration in fundi. Arms and trunk normal. Hypertonia left leg, bilateral contracture gastrocnemii, foot deformity left. Exaggerated knee and ankle jerks, bilateral extensor plantars. Vibration diminished right ankle, absent left.

II.12 M. Killed 1914-1918 war. Said to be normal.

II.13 F. Age 46. Dragging right leg two years, increasing, now affecting left. Loses control walking downhill. Right leg jumps and flexes at night. Chronic bronchitis. Discs pink and indistinct but probably normal. Arms normal except much exaggeration of reflexes. Gross spasticity legs, contracture gastrocnemii worse on right. Weakness hip movements and dorsiflexors of ankle. Knee jerks grossly exaggerated and clonic. Ankle jerks difficult to elicit owing to contractures. Bilateral extensor plantars. Bilateral defect vibration sense ; defect of joint sense right. Grossly spastic gait. Crepitus at knees. Marked euphoria in face of considerable disability.

II.14 M. Died at birth. Exact position in family uncertain.

\section{Generation III (36 members)}

(III.1-8. Offspring of II.1)

III.1 F. Age 44. Legs give way at knee. Others say she walks as if about to fall. Cranial nerves and arms normal except great increase in reflexes. Abdominals absent. Bilateral hypertonia in legs with weakness dorsiflexion right foot. Marked exaggeration knee jerks with patella clonus ; exaggerated ankle jerks. Right plantar extensor; left equivocal. No ataxia.

III.2 M. Died at one month, cause unknown.

III.3 M. Age 41. No complaints except clicking (C 80288) and swelling left knee and bronchitis. Obese. Bronchitic signs in chest. Cranial nerves and arms normal except much exaggeration of reflexes. Abdominals present. Slight hypertonia left leg. Weakness left knee. Gross 
exaggeration knee and ankle jerks. Both plantars abnormal. "Possibly very slight ataxia."

III.4 M. Always unstable. Severed connexions with family and committed suicide at date unknown. Not known to have been affected.

\section{III.5 F. Died at birth.}

III.6 F. Died at age 28 of tuberculosis. Not known to have been affected.

III.7 F. Died aged 28 of pneumonia (? tuberculosis). Not known to have been affected.

III.8 M. Died aged one month. Cause unknown.

III.9 F. Age 35. Only daughter of II.4. Ankles swelling 10 years, more recently letting her down. Knees and ankles stiffened. Paræsthesiæ at night with cramps. Obese. Bilateral œdema of ankles. Heart and kidneys normal. Cranial nerves normal. Marked exaggeration arm reflexes. Abdominals present. Increased tone right leg with mild foot deformity. Marked exaggeration knee and ankle jerks with bilateral extensor plantars.

\section{(III.10-12. Offspring of II.5)}

III.10 M. Age 33. Widespread rheumatism. Rejected from Army for reputed heart disease. Slight stiffness in legs when cold. Heavily built. No abnormality in any system apart from very brisk reflexes. (Not considered affected.)

III.11 M. Age 26. No definite complaints. Cranial (C 80957) nerves, arms, and abdomen normal. Knee jerks brisk ; ankle jerks exaggerated. Right plantar flexor; left probably extensor; Oppenheim extensor. Vibration markedly diminished both ankles; slightly at knees. Foot deformity more of true pes cavus type than in other cases.

III.12 M. Killed 1939-45 war. " An unusually fine physical specimen."

III.13 M. Age 35. Son of II.6. No complaints. Cranial nerves, arms and trunk normal. Slight hypertonia of legs. Marked exaggeration knee and ankle jerks with ankle clonus. Plantars flexor. Bilateral foot deformity.

\section{(III.14-22. Offspring of II.7)}

III.14 M. Age 41. Occasional unpredictable (C 85160) attacks of numbness in legs. Cranial nerves normal except middle-ear deafness left. Arms, marked exaggeration reflexes. Left upper abdominal reflex very weak. Characteristic foot deformity with early contracture tendo-achilles. Hypertonia, left more than right, with gross exaggeration knee jerks and patella clonus; exaggeration ankle jerks and ankle clonus. Both plantars apparently flexor. Gait, mildly spastic.
III.15 F. Age 40. No definite abnormality.

III.16 M. Age 39. Legs felt heavy on rising in morning for years. Occasional paræsthesiæ. Cranial nerves normal. Left arm reflexes brisker than right. Abdominals normal. Mild bilateral foot deformity. Left knee and ankle jerks definitely brisker than right. Left plantar extensor. Vibration diminished left.

III.17 M. Not examined but said by brothers to be unaffected.

III.18 M. Died of jaundice, ætiology unknown, aged $2 \frac{1}{2}$.

III.19 M. Died of croup, age unknown.

III.20 M. Age 30. Feet shake uncontrollably on weight-bearing. Some visual failure but no sudden loss. Fundi, right normal; left disc very sharply outlined with pale segment at 7 o'clock, significance doubtful. No field change. Arms, marked exaggeration reflexes. Abdominals, right weak; left almost unobtainable. Deep reflexes exaggerated. Knee and ankle jerks much exaggerated with patella and ankle clonus. Plantars flexor.

III.21 F. Died shortly after birth of congenital heart disease.

III.22 F. Age 23. Left leg heavy and letting her down for two years. Some vague paræsthesia. Obesity, particularly of hips and thighs Cranial nerves, arms and legs normal excepto for very brisk reflexes. (A very doubtful case - symptoms similar to the early stages of the disease but no definite objective evidence.)

(III.23-26. Offspring of II.8)

III.23 F. Alive, healthy, living in India. Not affected.

III.24 M. Healthy, living too far away to be examined. Not affected.

III.25 M. Age 25. No complaints and no abnor(G 273041) mal signs except very brisk arm reflexes and gross exaggeration knee jerks. (Not considered sufficient evidence of affection.)

III.26 M. Age 23. No complaints. Cranial nerves normal. Slight weakness left arm. Reflexes brisker left than right and slightly exaggerated. Abdominals normal. Tone slightly increased left leg with slight weakness. Knee and ankle jerks markedly exaggerated, much more so on left. Left plantar abnormal. Oppenheim extensor.

\section{(III.27-29. Offspring of II.9)}

III.27 M. Age 33. Occasional dragging legs since (G 265267) 27. Numbness of feet during $5 \frac{1}{2}$ years in Army. Discharged owing to bronchitis. Seen first November, 1948. Cranial nerves, arms and trunk normal. Legs, bilateral increased tone and weakness dorsiflexion feet. Knee 
and ankle jerks markedly exaggerated. Bilateral extensor plantars. Bilateral characteristic foot deformity. No ataxia. Seen again July, 1949. Signs and symptoms unchanged but left disc margin blurred and vessels humped. (This appearance, though of doubtful significance, was not present on previous examination.) Admitted Dudley Road Hospital, Birmingham, April, 1948, and extensively investigated, the only abnormality being a histamine-fast achlorhydria.

III.28 M. Died 1937, aged 23, of " meningitis". Obscure multiple contractures of hamstrings, adductors of thighs, and gastrocnemii since early infancy. Treated orthopædically with varying success, all contractures repeatedly recurring during growth. No full neurological examination available, but marked spasticity noted and diagnosed as "spastic diplegia of obscure origin ".

III.29 M. Age 28. Quite fit ; no abnormal signs.

\section{(III.30-32. Offspring of II.10)}

III.30 F. Age 36. No complaints. The only abnormality on physical examination was so gross an exaggeration of all tendon reflexes as to render her highly suspicious of being a subject of early disease.

III.31 M. Age 29. No complaints ; no abnormal signs.

III.32 M. Not examined but considered by brother to be normal.

III.33 M. Age 31. Son of II.11. No subjective complaints. Cranial nerves, arms, abdomen normal. Slight hypertonia, legs. Marked exaggeration knee and ankle jerks with sustained ankle clonus. Right plantar abnormal. Characteristic foot deformity bilateral.

\section{III.34 M. Son of II.12. Not traced.}

\section{(III.35-36. Offspring of II.13)}

III.35 M. Age 23. Illness diagnosed as polio(G 272482) myelitis aged 2. Slight limp left leg since, but served in Royal Marines during 1939-45 war. Cranial nerves and arms normal except for very brisk reflexes. Trunk normal. Slight wasting both thighs with weakness quadriceps. Right knee jerk weak, others normal. Bilateral ordinary pes cavus. (These signs presumed to be sequelæ of poliomyelitis.)

III.36 F. Age 21. No complaints. Normal (G 273040) examination except very brisk knee and ankle reflexes with ankle clonus. (Not sufficient evidence to consider affected.)

\section{Generation IV (26 members)}

IV.1 F. Daughter of III.1. Age 21. Normal.
(IV.2 and 3. Offspring of III.3)

IV.2 M. On active service. Said by father to be normal.

IV.3 F. Age 18. Said to walk like her father. Right ankle gives way. Gross obesity since childhood. Frequency of micturition and polyuria. Chronic bronchitis. Obesity of pituitary type. No abnormality in central nervous system apart from weakness dorsiflexion right ankle. (History suspicious, but signs insufficient to include among early cases.)

IV.4 and IV.5 Son and daughter of III.4. Both grossly obese and well-known in their district as "freaks". Not seen, but no suggestion of disease.

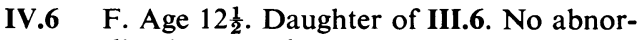
mality in central nervous system. Signs in heart suggest patent inter-ventricular septum.

(IV.7 and 8. Offspring of III.10)

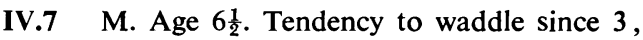
the only abnormality on examination being pes planus.

IV.8 F. Age 3. Walked early and said to be " double-jointed". Examination revealed no abnormality except for occasional extensor element to left plantar-probably voluntary.

(IV.9 and 10. Offspring of III.14)

IV.9 F. Age 17. No abnormality in central nervous system. Loud and harsh systolic murmur over the whole precordiumpossible septal defect.

IV.10 M. Age 8. Normal.

IV.11 F. Age 14. Daughter of III.15. Lobar pneumonia with meningism at age 4 . Complete recovery. Some stiffness following exertion recently. Cranial nerves and arms normal except for exaggerated supinator jerks. Left abdominal reflexes very weak. Left foot smaller than right. Both knee and ankle jerks exaggerated. Left plantar abnormal. Oppenheim extensor.

IV.12 and IV.13 M. and F. Children of III.16. Both quite normal.

IV.14 M. Son of III.17. Not seen. Said by uncles to be normal.

IV.15 and IV.16 M. and F. Children of III.23 and III.24 respectively. Lived too far away to be examined, but said to be normal.

\section{(IV.17 and 18. Offspring of III.27)}

IV.17 M. Age 9. Well to March, 1948, when lost (G 265268) sight of left eye suddenly. Seen at Birmingham Eye Hospital. Had papillœdema left disc, and no perception of light. Right eye 
and field normal. All relevant investigations negative. Gradual recovery of sight and regression of papillœdema, with appearance of pallor of disc. Seen personally Nov., 1948. No abnormal signs except pallor left disc. Va., left $6 / 24$, right $6 / 9$. Seen again July, 1949, left disc now showing definite optic atrophy and right possibly paler than normal. Va., left $6 / 24$, right $6 / 9$. Fields : not very reliable subject but only slight indrawing of all isopters, a little more marked in left lower nasal field. Colour vision impaired centrally but no true scotoma detected.

IV.18 M. Age $2 \frac{1}{2}$. Late walking. Drags feet and (G 264128) trips easily. Never straightens right knee. Wears out toes of shoes. Said to be normal mentally. Examination very unsatisfactory when first seen (Oct., 1948), but reviewed July, 1949 (age 3), when condition had progressed to bilateral foot-drop, and uncontrollable shaking of limbs when riding tricycle. Cranial nerves normal. Slight hypertonia arms. Commencing contracture gastrocnemii producing limitation dorsiflexion feet. Hamstring contracture also developing. Tone increased, left more than right. Gross exaggeration of reflexes, left more than right, with bilateral ankle clonus. Left plantar extensor.

\section{(IV.19-21. Offspring of III.30)}

IV.19 M. Died in infancy. Cause unknown.

IV.20 M. Age 9. Normal.

IV.21 M. Age 7. Sudden inability to see blackboard on day before examination. No definite abnormality in central nervous system apart from fundi. Could not read largest type. Bilateral myopia. Both discs pale. Both disc margins very blurred and vessels humped as they enter disc. Re-examined in total darkness with same impression. Reviewed five months later. Refractive error corrected with some improvement in acuity. R. 6/12 L. 6/36. Right disc now clearly seen. Left disc still very blurred and vessels humped at edges. Too young to co-operate in examination of fields.

\section{(IV.22-24. Offspring of III.31)}

IV.22 F. Age 10. No abnormalities.

IV.23 F. Age $2 \frac{1}{2}$. No definite abnormality on examination except for plantar reflexes which gave consistently extensor responses. (This was so definite that considered possibly incipient disease.)

IV.24 F. Age 10 months. Reflexes all very brisk, otherwise normal.
(IV.25 and 26. Offspring of III.35)

IV.25 M. Age 4. Normal.

IV.26 M. Age 5 months. No abnormality on limited examination.

\section{Analysis of Clinical Data}

This family illustrates how widespread the disease may be throughout its various members. Of the 76 individuals who make up the three generations, 27 were affected either in major or minor degree, the fully-developed syndrome being present in 18, and possibly in one other who had died, while incipient disease was present in 7 , and possibly in two others. Ocular defects alone were found in two.

Nine of the fourteen members of Generation II were affected, eight known to have shown the fully-developed syndrome. In Generation III (36 members), eight of the thirteen affected were considered to show the complete picture though generally in a milder form or stage than their forebears. Of the 26 members of the fourth generation, one was severely affected; one (and possibly one other) had the abortive or early form, and two had signs referable to the eyes only.

The severity of the disease appeared to haveo diminished in successive generations. This may be due to a natural tendency for the disease to die out, or to be referable only to the earlier age at which the patients were seen, the disease being progressive. Nevertheless one of the most severely affected patients was IV.18, 3 years old when examined, while III.28 was severely affected from the first month of life.

The character of the disease remained constant in Generations II and III, but the appearance of retrobulbar neuritis with papillœdema in the fourth generation may indicate an alteration in the maximal, or perhaps the first, site of affection. It will be valuable to follow these children through their early adult life to detect the early stages of any neurological disease which may later develop.

The age at which the disease was discovered was earlier in each successive generation. It is not justifiable, however, to draw from this any conclusions regarding the age of onset, for in Generations III and IV knowledge that their family bore an affliction prompted earlier recognition of symptoms. Yet even so, the knowledge that the disease progresses, and its discovery in minor form in symptomless subjects, does suggest that in most of the established cases the onset of symptoms came considerably later than the first objective evidence of the disease, had the latter been sought.

In Generation II the average age of onset of symptoms was 45 , with limits 36 and 56 . In 
Generation III so few gave any clear history of onset of symptoms that little reliability could be attached to any attempt to find a mean age. Three members however recognized symptoms at ages between 25 and 30 and the average age at which the affected members of this generation were discovered was 34 , with limits 23 and 44 . (This is omitting III.28 who was affected from infancy.) The two children of Generation IV who were affected with the same syndrome as their relatives were aged 14 and 3 respectively, while the two boys with ocular changes were 9 and 6 respectively.

Eighteen males and eight females were affected, there being 48 male and 28 female members in the three generations, which figures show only a slightly greater tendency for the male sex to be affected. It is apparent that the disease can be transmitted through either sex, and in one instance only was it found in the offspring of a clinically normal parent. This may apply also to another branch of the family in which the father, now dead, was not examined, but was reputed to be normal. The finding of so many who had objective evidence of disease unsuspected by themselves or their relatives led one, however, to view such assertions of normality with suspicion.

Symptomatology.-The symptomatology of the disease was in many cases masked by associated conditions some of which may well have been secondary effects of the basic disorder. Chronic arthritis of the knees was, for instance, the main complaint of four of Generation II, was present to a marked degree in another member, and pain around the knees and crepitus on movement were frequent findings. It is not difficult to understand how repeated minor (and major) traumata which affect the joints of a spastic limb may result in a traumatic osteo-arthritis, such as was so marked in II.5 that the underlying spasticity was originally completely unsuspected. Otherwise however the main symptoms were stiffness, especially on climbing stairs ; dragging the feet; tripping over the pavement; giving way at the ankles; uncontrollable shaking when weight is placed on the feet ; flexing and jumping of the legs at night; heaviness of the feet ; and contractures. The term "unsteadiness" was used by three patients, each of whom said this was only on going downhill, and as no demonstrable ataxia was present, either in gait or in tests of coordination, it seems possible that the retardation of movement in the spastic limb was responsible for this symptom. Five patients complained of numbness in the legs, but in no case was any superficial sensory loss discovered. Weakness was complained of by one patient only. Sudden inability to see the blackboard at school was the complaint of the two children with ocular disturbances. In the younger the presence of a myopia made this of doubtful significance, but the elder developed a large central scotoma which gradually cleared.

Abnormal Signs.- These have already been mentioned under the heading "criteria for diagnosis" and will not be repeated in detail here. Spasticity, grossly exaggerated reflexes, abnormal plantar responses, and, in eight cases, the characteristic foot deformity mentioned above, were the main abnormalities, while vibration sense was defective in the legs in seven cases and contractures were present in five. Weakness was found in seven cases only, and in some of the most severely spastic limbs remarkably good power was maintained. The abdominal reflexes were weak or absent in six cases, while the arms were affected in 13 . In 13 of the cases who were personally examined, there was a predominance of affection to one side or the other. It is interesting to note that this was the left side in 11 of these 13 cases, and in two of these the picture was that of a left hemiplegia, the right side being almost completely normal. Similarly it was noted that in the five patients in whom ophthalmoscopic abnormalities were recorded, the left eye was affected in each case. Euphoria was a feature of several of the affected individuals and in four cases was quite an outstanding sign.

The only cranial nerve abnormalities were referable to the eyes. The most definite and dramatic sign was found in IV.17, who, seen four days after a sudden loss of vision of the left eye, was shown to have a mild papillœdema, with no perception of light and only a sluggish pupil reaction. Three weeks later he could count fingers, and two months later vision was $6 / 24$, the œdema had cleared, being replaced by a definite pallor. Sixteen months after the onset visual acuity was R.6/9, L.6/24, the right disc was slightly pale and the left showed definite optic atrophy. Perimetry showed a slight depression of the peripheral fields to $1-3 / 330$, a little more marked in the lower nasal quadrant. A consecutive atrophy with diminished acuity could account for these slight changes, and no scotoma was demonstrated, though colour vision was defective. The boy was a poor subject for scotometry, and the fields cannot be considered completely reliable. Case IV.21 was seen the day after he complained of inability to see the blackboard, and had a definite myopia with pallor of the discs, but the edges of the discs were very blurred, and the vessels were humped as they entered. Five months later vision was improved slightly with spectacles, and the right disc was clearly seen. The 
left was still very blurred and the vessels appeared to be humped. Two other patients showed blurring of the discs on the left side, which in one patient personally examined twice at ten months' interval was not present on the first occasion. In neither case was there definite visual impairment, and they were not diagnosed as retrobulbar neuritis. It is interesting however that these two were the father and the grandfather of the definite case of retrobulbar neuritis (IV.17).

Associated Abnormalities.-Arthritis of the knees was severe in five cases, four of these being in Generation II. Case II.5 was so severely affected that the underlying neurological condition had been effectively masked. A milder degree of arthritis was present in many of Generation III.

Obesity of severe enough degree to be disabling was present in eight patients. Case II.1 was said to be very obese, but the most gross examples of obesity appeared in those members of the fourth generation having II.1 as a common ancestor. Cases IV. 4 and 5 were well-known in their own area as "freaks" because of their enormous size, and IV.3, older, but similar in appearance, had, in addition, increased frequency of micturition and polyuria. None complained of any menstrual disturbances.

Chronic bronchitis was widespread throughout the families descending from II.1, and occurred not infrequently in other members. Tuberculosis was contracted by four individuals, two of whom, and possibly a third, died of the condition.

Congenital heart disease was known to be the cause of death of III.21, and the clinical diagnosis of a patent interventricular septum was made in IV.6 and IV.9. Many babies had died shortly after birth from causes in most cases unknown : it is possible that some of these may have had congenital abnormalities, but there were no others discovered in the patients examined, except for crooking of the little finger. This was observed in several instances, but unfortunately no precise note of this was made, and the frequency is uncertain. A similar deformity is mentioned by Bell and Carmichael (1939).

Laboratory Investigations.-The whole of this review was carried out at an out-patient clinic and C.S.F. findings are known in two cases only, namely II.9 and his son, III.27. These were normal. Wassermann tests were done on seven affected patients and were all negative.

Course.-One patient only (II.9) was observed for more than a year, and one has to judge from the history and relatives' reports as to the progress of the disease. In general the impression was gained that those who became affected after adult life with the fully-developed syndrome reached a maximum disability gradually over the ten-year period following the onset, after which the condition remained stationary or progressed only very slowly, and in several patients was an annoyance rather than a very grave disability. In not one case could death have been attributed to the disease. Onset of the disease in childhood or during the period of growth was more serious, for the contractures which tended to develop needed frequent correction and usually recurred. Those who had developed to an advanced stage showed a remarkable similarity of clinical picture, a similarity that was enhanced by the striking facial resemblance between many members of the family. It was interesting that III.29, coming to the clinic, by coincidence, on the same afternoon as II.8, his uncle, recognized him immediately from his resemblance in appearance, posture and gait to his own father (II.9), despite the fact that II.8 had left for India before III.29 was born, and the latter had no idea that he had ever returned to this country.

\section{Discussion}

In the last 100 years the heredo-familial diseases of the nervous system have been the subject of much interest and a steadily growing volume of literature. The comparative rarity of widely affected families, the sparsity of necropsy material, the ignorance as to atiology, and the remarkable variety of the syndromes described, has led to much theorizing as to their fundamental nature and their possible inter-relationship. Opinions on the latter can be grouped in general into three : the two extremes who consider $(a)$ that each syndrome is a separate genetic entity, a view held now by only very few ; or $(b)$ that all the syndromes are but different manifestations of the same process, the features being determined by the particular part of the nervous system affected. The third class of opinion includes those who feel that the majority of the ataxias are variations of the same process, while some of the other heredo-familial disorders, including hereditary spastic paraplegia, are separate entities. Bell and Carmichael (1939), for instance, consider Friedreich's ataxia and the spastic ataxias due to the same gene under the influence of modifiers, but are less certain about hereditary spastic paraplegia. Calculations regarding the sex, distribution, average total duration of illness, and age at death provided evidence in favour of genetic interrelationship, but clinically they were unable to find records of spastic paraplegia occurring in the same stock as the ataxias. 
Haldane (1941 $a$ and $b$ ) and Sjøgren (1943) differ as to whether the three have a common genetic basis or whether the ataxias must be separated into different genotypes.

From the purely clinical point of view, the strongest evidence for associating the various heredo-familial disorders is the existence of two or more different varieties in the same family, and of transicion forms between two different varieties in the same individual. Friedreich's ataxia, and the clinically very different spastic ataxias, present little difficulty in this respect, and Bell and Carmichael (1939) were able to find 32 families in which both types of disease occurred. Roth (1948) recently has described two families in which association is suggested between Friedreich's ataxia and CharcotMarie-Tooth's disease in one, and between these two and Marie's ataxia in the other. In his paper published work is mentioned associating (a) Friedreich's ataxia, spastic ataxia, and spastic paraplegia ; (b) Friedreich's ataxia and Charcot-Marie-Tooth's disease ; $(c)$ Friedreich's ataxia and the myopathies ; (d) Friedreich's ataxia and a form of optic atrophy clinically similar to that described by Leber; and (e) neurological disorders and other congenital abnormalities. To this we can add the family of Philip (1886) in which occurred both myopathy and spastic paraplegia, and the views expressed by Rhein (1916) that transition forms exist between the pure spastic paraplegias and those with ataxia or muscular atrophy, and by Deléarde and Minet (1908) that all forms exist between hereditary spastic paraplegia, familial amyotrophic lateral sclerosis, familial cerebral diplegia, and familial disseminated sclerosis.

It has already been mentioned that any record of overlap in the same stock between the ataxias and the pure spastic paraplegia is difficult to find. Ballet and Rose (1905) and Raymond and Rose (1909) considered their cases, however, to show transition from the spastic ataxias to hereditary spastic paraplegia, and Bell and Carmichael (1939) suggest that a careful search among the siblings of spastic paraplegics might uncover signs of ataxia in some. It was notable in this family that this did not occur. Cases of minor or minimal disease were discovered, but the clinical picture in each case was that of the fully-developed disease at an earlier stage, or of lesser severity, and in two cases only was a very slight and most dubious ataxia recorded. One of these was not examined personally, and both were severely involved in the fully-developed spastic process and had some difficulty in executing the tests for co-ordination. No further direct evidence can be deduced from this study of association between the hereditary ataxias and hereditary spastic paraplegia.
It is interesting to note that II.9 was at one time considered to be an example of amyotrophic lateral sclerosis. He had wasting of the thigh of one leg, and of the thenar eminences, and had weakness of the right hand and of both legs, with spastic paraplegia. One can go no further, on the evidence of one isolated example, than to suggest that the process affecting this family and producing typical examples of hereditary spastic paraplegia, may also be the cause of this local muscle wasting.

The picture of a cerebral diplegia, occurring at, or immediately after birth, was produced in one member of the family, and this suggests that families afflicted early enough with the manifestations of this disease could show the picture of familial cerebral diplegia, without having to indict some other specific process.

The occurrence of retrobulbar neuritis progressing to atrophy in this family forces one further to consider possible connexions between hereditary spastic paraplegia and Leber's optic atrophy, or even disseminated sclerosis. Johnson Taylor (1892), Behr (1909), Takashima (1913), Imamura and Ichikawa (1919), and Ferguson and Critchley (1928), have all reported the heredo-familial occurrence of optic atrophy, often bilateral, with dense central or centro-cæcal scotomata, following in some cases a known swelling of the discs and associated with signs elsewhere in the nervous system, including pyramidal signs and ataxia, and Behr considered his cases a transition between Leber's disease and Strümpell's on the one hand, and the heredoataxias on the other (a view which would be disputed by those who consider Leber's optic atrophy a disease essentially and specifically confined to the optic nerves). Though the optic discs in IV.17 had developed a definite optic atrophy following the initial papillœdema, yet the good return of vision, and the absence of any gross field defect are points very much against this being an example of Leber's disease. Is it, rather, the early stage of disseminated sclerosis? If this child were to develop pyramidal signs later in life, the previous history of retrobulbar neuritis would almost inevitably lead to a diagnosis of disseminated sclerosis. It might be emphasized here that euphoria was a marked sign in several of the severely affected cases.

Though this association of papillœdema and hereditary spastic paraplegia is extremely rare, it has been noted previously. Bremer (1922) described two families with hereditary spastic paraplegia, in the second of which two members had optic atrophy and one a swelling of the disc. Kastan (1945) in a paper concerning a family showing spastic paraplegia, Pelizæus-Merzbacher disease and leucodystrophy in different members. mentioned 
one child who was seen to have blurred discs in 1939 and optic atrophy in 1940.

André-van Leeuwen and van Bogaert (1949) have recently discussed the question of the association of what they term the " retrobulbar neuritis" type of optic atrophy with the hereditary ataxias. Their differentiation from other types rests on the presence of central, centrocæcal or paracentral scotomata. They ask whether this type "is really as rare in hereditary ataxia as it seems at first sight to be". It appears from their review that if careful visual field examinations were made in all cases of optic atrophy in hereditary disorders of the nervous system, this type might not infrequently be demonstrated, and from the family under consideration now, it appears probable that many of these, if seen early enough, might show œdema of the nerve head, its presence possibly being controlled by the anatomical relationship of the lesion to the disc.

The fundamental cause of the chromosomal modification which is responsible for the explosive appearance of the condition in one generation remains unknown. If we are to ignore the very dubious story of affection of a member of Generation I, we must consider Generation II as being the first to show evidence of what becomes a dominant genetic characteristic. Consanguinity was unknown in the family. Alcoholism has often been indicted by the earlier writers, and though it is known that Generation II, as children, were reared under the worst social conditions, and that their father was " fond of the bottle" no gross degree of alcohol addiction is suggested. There has been no evidence of syphilitic disease in any member.

To the mathematician and geneticist, families such as this form an interesting study from which careful search may provide a wealth of material, but even here, where it has been possible to examine so many members, figures are bound to be unreliable, for if so many who are reputed to be normal can be found to be affected, assurances as to normality of deceased relatives are bound to be open to question Nor can we know how many of those children who died in infancy would have developed signs of the disease in later life. Their observations may, however, be of great assistance to the clinician who is faced with the patient's anxiety regarding the danger of transmission of the disease, or of the disease developing in unaffected members at a later date. Statistics suggest that the age of onset of these conditions is within fairly narrow limits for a particular sibship, and older members, if unaffected, may consider their outlook more favourable. A completely confident answer cannot however be given, and this family illustrates the presence of definite signs of the disease in apparently unaffected members who are past the average age of onset. Whether these are early cases of a progressive disease, or abortive cases which will progress no further, can only be decided by long-term observation, but their presence demonstrates how important it is in investigating such a family, to examine such patients in detail, and not merely to rely on relatives' statements.

Can the appearance of retrobulbar neuritis and optic atrophy in the fourth generation be purely coincidental? It is difficult to believe this, when we know optic atrophy to be so characteristic a feature of many of the hereditary disorders of the nervous system. Whether it indicates a change in character of the disease itself, or merely of the site of maximal (or earliest) affection, cannot be determined until the progress of these children has been watched for many years. It appears however that the same process, possibly altered by modifying genes or by environment, is capable of producing a series of closely related clinical syndromes, varying mainly in the site of maximal affection. Some show evidence of familial amyotrophic lateral sclerosis ; some of familial diplegia ; some appear to be the earliest stage of disseminated sclerosis; and the remainder are typical of the hereditary spastic paraplegia. Extending this hypothesis beyond the affections of the pyramidal tracts-and the posterior columns were affected in several of this present family-it is not difficult to imagine an infinite variety of ataxias, paraplegias, and amyotrophies,? grouped together on a closely related genetic basis, and in this way to simplify the confusion of syndromes which at present overburdens the literature.

\section{Summary}

A family is described in detail in which hereditary spastic paraplegia is unusually widespread throughout three generations.

Careful search among apparently normal members of the family has uncovered several examples of early or abortive disease.

Eighteen individuals have been affected with the fully-developed syndrome, while seven have shown signs of incipient disease.

One child had a retrobulbar neuritis with papillœdema which progressed to optic atrophy, leaving diminished visual acuity, but practically normal visual fields. One other child is probably affected in the same manner and two adults have been suspected of having swollen optic discs.

Some members showed a picture similar to cerebral diplegia, and in one case to amyotrophic lateral sclerosis. 
It is suggested that this family gives further support to the view that the heredo-familial disorders of the nervous system are inter-related.

Without the ready co-operation of the members of the F. family this work would not have been possible. I wish also to acknowledge the assistance given by Mr. G. M. Barling, late of the Birmingham Eye Hospital ; Mr. M. James, of the Royal Cripples Hospital, and Dr. H. M. D. Shepherd, of Dudley Road Hospital, who supplied details of the patients who had passed through their hands.

In particular my gratitude is due to Professor P. C. P. Cloake, who first drew my attention to this family, in whose clinic all the patients were seen, and who has given encouragement throughout, and to Dr. E. Arnold Carmichael and Dr. Julia Bell, whose criticism was invaluable.

\section{REFERENCES}

André-van Leeuwen, M., and Bogaert, L. van (1949). Brain, 72, 340.

Appel, L. (1949). Acta. Neurol. Psychiat. Belg., 49, 415.

Ballet, G., and Rose, F. (1905). Nouv. Iconogr. Salpêt., 18, 404.

Behr, C. (1909). Klin. Mbl. Augenheilk., 47, 138.

Bell, J. (1933). "Treasury of Human Inheritance." Cambridge Univ. Press, 2, Part IV.

- , and Carmichael, E. A. (1939). Ibid., 4, Part III.

Bremer, F. W. (1922). Arch. Psychiat. Nervenkr., 66, 477.
Deléarde, A., and Minet, J. (1908). Rev. Médecine, 28, 181.

Dobrochotow, M. (1913). Dtsch. Z. Nervenheilk., 49, 1.

Ferguson, F. R., and Critchley, MacD. (1928). $J$ Neurol. Psychopath., 9, 120.

Gee, S. (1889). St. Bart's Hosp. med. Rep., 25, 81.

Haldane, J. B. S. (1941a). J. Genet., 41, 141. (1941b). Ibid., 41, 149.

Holmes, G. (1905). Rev. Neurol. Psychiat., 3, 256.

Imamura, S., and Ichikawa, K. (1919). Rev. neurol., 26, 277.

Jones, E. (1907). Rev. Neurol. Psychiat., 5, 98.

Kastan, M. (1945). J. nerv. ment. Dis., $101,357$.

Manson, J. S. (1920). Brit. med. J., 2, 477.

Ogilvie, G. (1908). Proc. R. Soc. Med., 1, 91.

Paskind, H. A., and Stone, T. T. (1933). Arch. Neurol. Psychiat., Chicago, 30, 481 .

Philip, R. W. (1886). Brain, 8, 520.

Raymond, F., and Rose, F. (1909). Encéphale, 1, 209.

Rhein, J. H. W. (1916). J. nerv. ment. Dis., 44, 115 and 224.

Roth, M. (1948). Brain, 71, 416.

Seeligmüller, O. (1876) Dtsch. med. Wschr., 2, 185.

Sjøgren, T. (1943). Acta. Psychiat. Kbh., Supplement 27.

Strümpell, A. (1880). Arch. Psychiat. Nervenkr., 10, 676.

Takashimá, S. (1913). Klin. Mbl. Augenheilk., 16, 714.

Taylor, S. Johnson (1892). Trans. ophthal. Soc. U.K., $12,146$.

Tooth, H. H. (1891). St. Bart's Hosp. med. Rep., $27,7$.

Worster-Drought, C., Greenfield, J. G., and McMenemy, W. K. (1940). Brain, 63, 237.

$-, \ldots,-(1944)$. Ibid., 67, 38. 